instrument the Palinurus after the pilot of Aeneas when he sailed in search of the empire promised him by the oracle. It is perhaps fitting that the instrument named after Palinurus is now forgotten, for his character does not bear comparison with that of Pelorus. He fell overboard when asleep and was three days in the water before he reached shore, only to be murdered by the inhabitants for the sake of his clothes. According to the ancient Roman religion no one whose body lay unburied could cross the Styx, but Aeneas when visiting the infernal regions met him and was able to promise him a magnificent monument and that the promontory should be called Palinurus after him, honours which he hardly seems to have deserved.

Some instrument makers still market 'Friend's Pelorus' and the name became transferred to most bearing plates similarly designed.

During the early years of this century some navies, particularly those of of France and the United States, designed the bridges of their warships in such a manner that it was difficult to take bearings from the standard compass except over a very limited arc. In consequence they fitted a Pelorus in each wing of the bridge in a metal column which, in America, naturally became called the Pelorus stand.

When the Sperry Company designed its first gyro-compass equipment for production they found it convenient to take the U.S. Navy Pelorus stand as a model and made the repeaters of such dimensions as to fit into it. The name Pelorus then became transferred from the stand to the repeater which it contained. This was first called the Pelorus Repeater and later simply the Pelorus. When Sperry started selling their compass equipments in Great Britain they brought the name back to its country of origin and it became established in its new role.

\title{
Chartwork in Small Craft
}

\author{
from J. Vendrell \\ (Master Mariner)
}

I. Having had for some time to navigate small craft in all weather in the western approaches to the Clyde and on the west coast of Britain, the writer would like to submit for the consideration of other small-craft navigators some modification in chartwork which has proved useful, especially in rough weather when parallel rulers are an abomination and flying dividers can be lethal.

2. On a violently moving platform the navigator can only work with maximum efficiency when he is himself chocked off in a position in which he is sheltered, has the widest possible field of view, can take bearings and can brace himself securely to leave both hands free to carry out a limited amount of geometrical plotting with reasonable accuracy. The obvious position is of course the fore part of the wheelhouse, where there is very seldom sufficient room for a fullsized chart table with all the frills and trimmings.

3. In his own craft, the writer, having selected a position suitable for everything but chartwork, set about to find an alternative to a full-sized chart table and instruments which could be used with convenience and accuracy in this position. The answer was found in $(a)$ chart frames; $(b)$ a 5 -in. Douglas protractor; 
(c) a scaled cellulose straight-edge; $(d)$ an air navigation drift computer. The chart frames were stowed in a specially constructed rack in the navigator's position and all the other items, together with notebook and pencil, were stowed in canvas pockets sewn on to the flap of an adjacent flag locker within arm's reach of the navigator.

4. The chart frames were specially prepared with a back of plywood to size $15 \frac{1}{2} \times 22$ in. on which a cut-out section of the chart in use was placed and covered with scratched cellulose sheeting. The chart and cellulose are held in place by a beading surround through-bolted to the back. Any scale of chart can be mounted in a frame but the ideal scale is of the order of $1 / 170,000$. Sufficient frames must be prepared in advance to cover the area in which the craft is navigating. The frame size detailed in these notes is not necessarily ideal but was selected as there existed a suitable mounting arrangement into which frames of this exact size could be readily shipped for use in the vertical position. The cellulose sheeting can be written on in ordinary black-lead pencil and the writing erased with an india-rubber.

5. The five-inch Douglas protractor is illustrated in the latest edition of the Admiralty Manual of Navigation. At first glance this instrument appears to be very limited in its use for chartwork but with very little practical experience it will be found to have more uses than either roller or expanding parallel rulers and it has the very great advantage that it can be used with one hand on a chart held in any plane and in spite of the most violent movement of the craft.

6. The scaled cellulose straight-edge is a home-made instrument cut from a length of the 0.04 in. scratched cellulose nitrate sheeting as is used on the chart frames. Approximately an inch wide and eighteen inches long, it is flexible and rides up over the beading of the chart frame when in use and provides a means of drawing extended lines beyond the scope of a single operation with the Douglas protractor. The straight-edge is scaled in pencil from the edge of the chart and provides a convenient means of measuring distance on the chart. In the writer's craft one particular chart scale is used more often than any other and it has been found convenient to engrave the straight-edge with this scale. The engraving, however, is confined to one edge, the other being left available for scaling by pencil when using charts of different scales.

7. The drift computer. There are several marks of this instrument, differing mainly in the scales. All its applications except those directed at the computation of true airspeed, have their counterpart in marine use. Its three main uses for small-craft navigation are:

(a) the rapid solution of current problems;

(b) the solution, by inspection, of speed-time-distance problems ;

(c) the approximate solution of radar collision problems.

8. Figure I illustrates the (now obsolete) R.A.F. Mark 4 Drift Computer. Both illustrations are of the face of the instrument and each shows a different side of the removable slide scale in use. Fig. I demonstrates the use of the instrument for the solution of current sailing problems. Fig. I (a) shows the instrument set for a craft of 14 knots steaming $000^{\circ}(\mathrm{T})$; a current is setting $050^{\circ}$ at 2 knots. This is set on the instrument by rotating the compass rose to bring $050^{\circ}$ to the lubber's line; the 2 -knot vector $(\mathrm{BC})$ can be drawn on the cellulose of the compass rose, through which the appropriate graduation of the slide scale can be seen. The instrument is then reset for a ship's head of $000^{\circ}$. 
In the illustration the whole sailing triangle is shown superimposed on the instrument and the situation is that of a ship sailing from A towards B at 14 knots. The current effect in one hour is such that the ship will arrive at $\mathrm{C}$ instead of $\mathrm{B}$ at the end of that time; by inspection, that is by counting out from the centre the radial lines of the slide scale, the track over the ground of the craft is seen to be $6^{\circ}$ to starboard of the intended course and track speed is indicated as $15^{\circ} 4$ knots (for clarity, the arcs representing decimals of a mile have been omitted).

Fig. I (b) illustrates the procedure for setting up the instrument for determining the course to steer to make good a required course. In this case it is

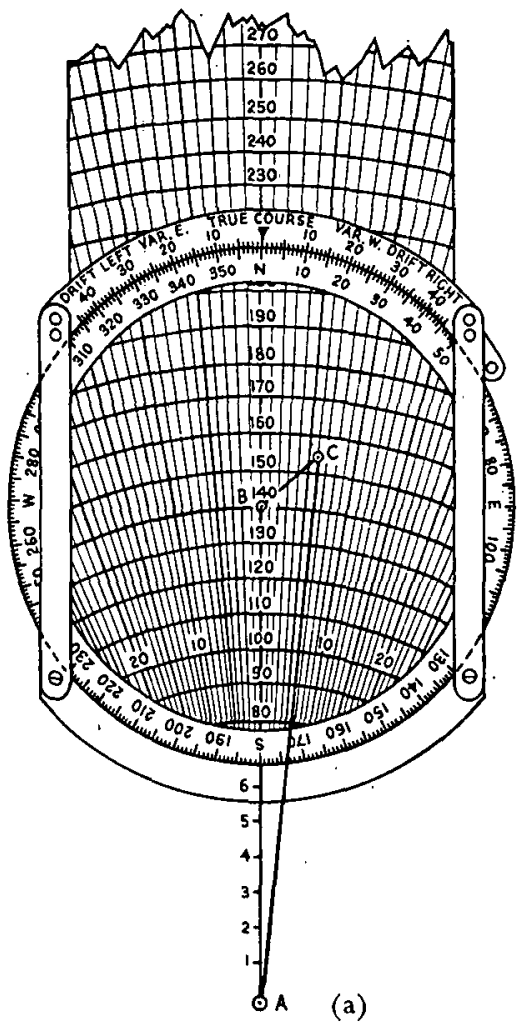

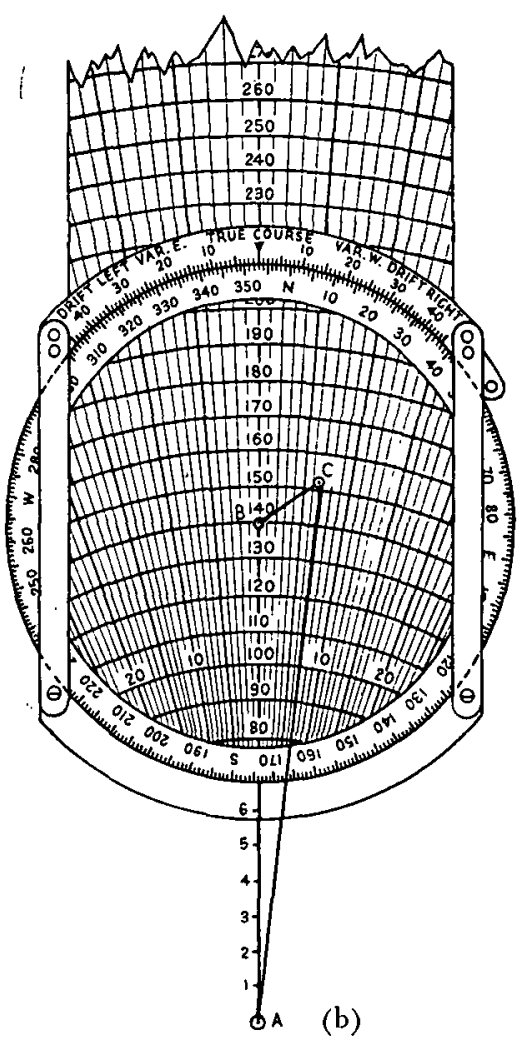

(b)

Fig. 1

required to make good a course of $000^{\circ}(\mathrm{T})$ with the same current. From Fig 1 (a) it was seen that a $6^{\circ}$ set to starboard was being experienced; the compass rose is therefore rotated to starboard in order to shift the lubber's point to port, appropriate to an alteration of course up into the current. When, however, the $6^{\circ}$ alteration of course to port has been set on the instrument it will be found that the act of rotating the compass rose has resulted also in a rotation of the vector $\mathrm{BC}$ and the point $\mathrm{C}$ is now $6 \frac{1}{2}^{\circ}$ (counting out the radial lines) from the course line. The instrument, therefore, must be adjusted until the throw-off for current is equal to the throw-off caused by the current and represented by the count of the radial lines out to the end of the vector line. When this adjustment is completed the instrument reads at the lubber's point 
the true course to steer in order to make good the required course. In practice, the whole sailing triangle does not appear on the instrument, but only the current vector. Moreover, the magnetic course to. steer is read directly off the instrument opposite the appropriate east or west variation engraved at the head of the instrument.

9. The use of the computer for the rapid and approximate solution of radar collision problems at sea is illustrated in Figs. 2 and 3 . Fig. 3 is a scale diagram showing two craft 14.3 miles apart at the start of the problem on

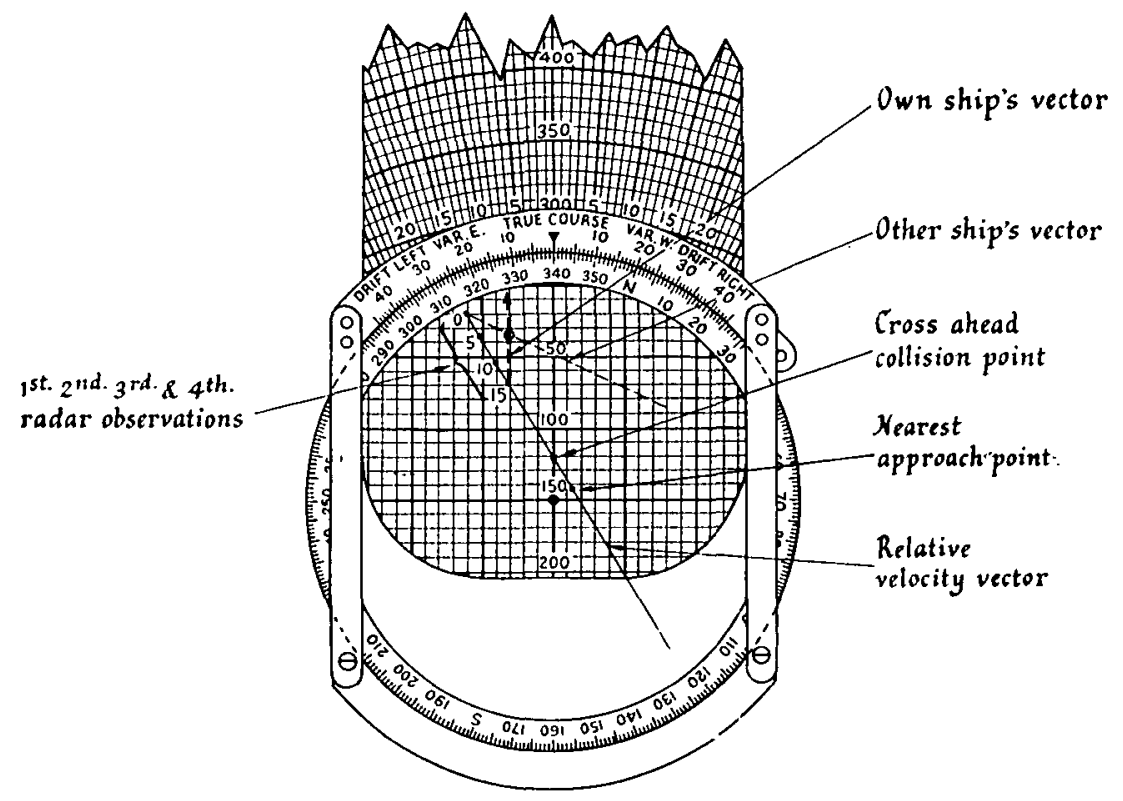

Fig. 2

a bearing from each other of $315^{\circ}-135^{\circ}$. Craft $A$ is steering $340^{\circ}(\mathrm{T})$ at 14 knots and observes craft $B$ on her radar screen. Bearings at five-minute intervals are plotted on the computer by aligning the instrument so that the bearing observed is placed against the lubber's point and a dot is pencilled on the cellulose surface of the compass rose against the appropriate scale of the graph on the slide scale. Four such observations are plotted in fifteen minutes in this example and the instrument is aligned to own ship's course. The relative-approach or velocity vector, is drawn through the observed points. From the speed-time-distance table at the back of the instrument it will be found that, at a setting of 14 knots, own craft has travelled a distance of 3.5 miles in 15 minutes. Accordingly, own craft's vector of 3.5 miles is drawn to scale as illustrated. It is now only necessary to complete the triangle as shown in Fig. 2 in order to obtain the other craft's vector which can then be evaluated in terms of length and direction by rotating the compass rose until this new vector is parallel to the fore-and-aft lines, and the athwartship lines of the graph are positioned below the vector so that the length can be read off by inspection.

From the diagram it will be seen that the direction of this vector will approximate $990^{\circ}$ with a length of 3 miles, which, when set against i 5 minutes on the 
speed-time-distance table, gives a speed of 12 knots. Thus in 15 minutes an assessment of other craft's movement is found to be $090^{\circ}$ at 12 knots. The relative approach or velocity vector can be similarly evaluated and the time at which one or other of the two craft will reach the collision point or the point of nearest approach can be rapidly determined.

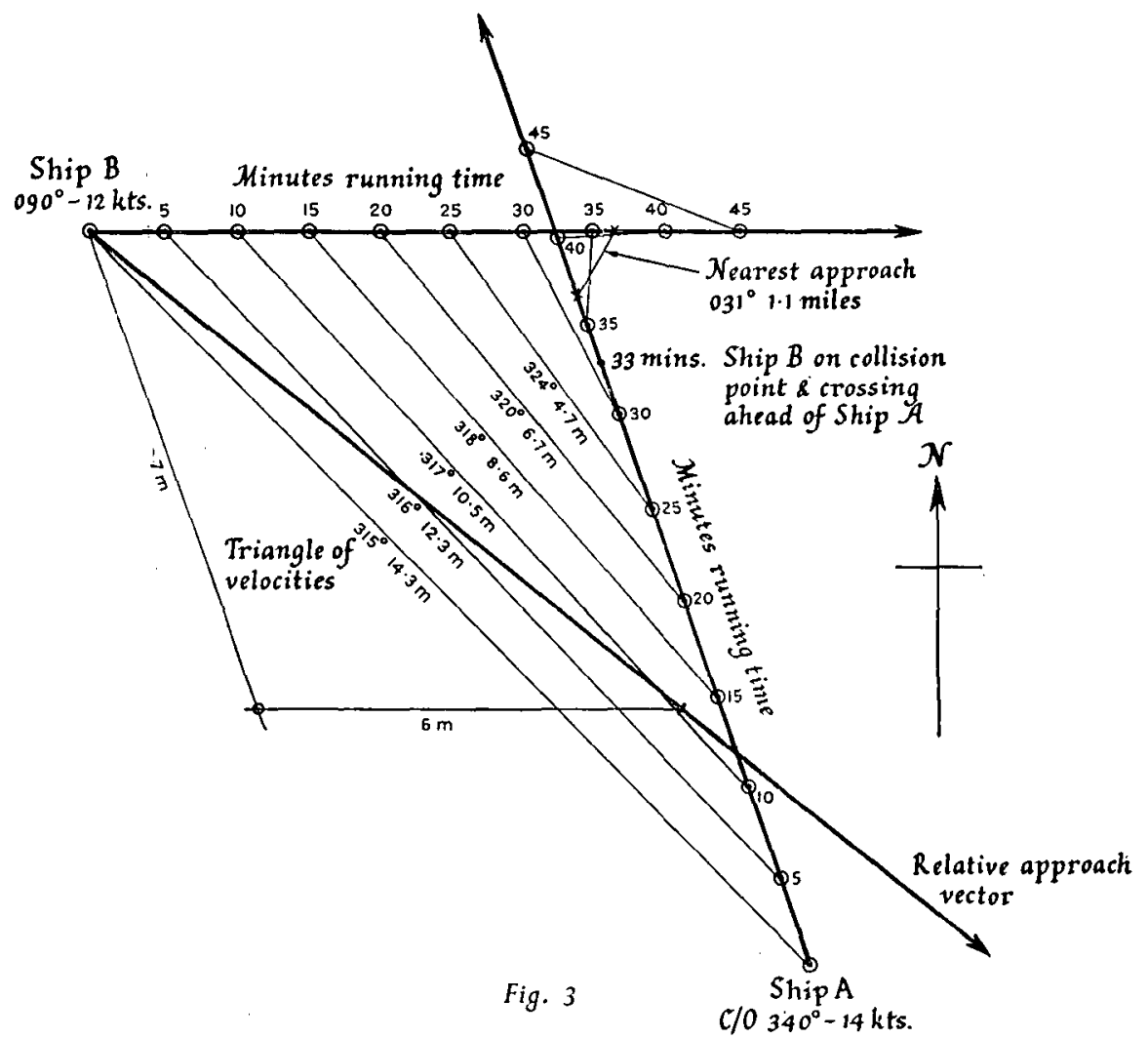

I०. Refinements in method will readily suggest themselves such as, for example, the possibility of laying-off own ship's vector in reverse from the first observation in order to make a more rapid appreciation of the situation at the second and subsequent observations. These, however, are outside the scope of these notes. 